\title{
Dominó do Heredograma: Encontro entre Signos das Ciências da Natureza e Matemática
}

\author{
Heredogram Domino: Integrating Symbols of Natural Sciences \\ and Mathematics
}

\author{
Andressa Venturini (dessaventurini8@gmail.com ) \\ Mestranda do Programa de pós-Graduação Ensino de Ciências e Matemática - Mestrado Profissional, \\ Universidade Franciscana
}

Rosemar de Fátima Vestena (rosemarvestena@ gmail.com )

Professor Doutora do Programa de pós-Graduação Ensino de Ciências e Matemática - Mestrado

Profissional, Universidade Franciscana

\begin{abstract}
Resumo: Objetiva-se nesse estudo apresentar um jogo de dominó, utilizando heredogramas como temática articuladora entre a área das Ciências da Natureza $(\mathrm{CN})$ e a área de Matemática (M). Trata-se de um produto educacional resultado da disciplina Ensino de Ciências e Matemática para Infância de um Mestrado Profissional de universidade do sul do Brasil. Foi construído um jogo de dominó envolvendo geometria e os signos dos heredogramas para facilitar a compreensão de conceitos da CN e M em perspectiva interdisciplinar. O Jogo foi aplicado junto a uma classe de estudantes e validado em um evento universitário. Portanto, após a aplicação e validação do jogo de "Dominó do heredograma" que explorou formas geométricas transpostas em símbolos empregado em heredogramas constatou-se que esse contribuiu positivamente no processo de ensino e aprendizagem dos estudantes e, dessa forma pode ser replicado e recontextualizado para outras situações de ensino e etapas escolares.
\end{abstract}

Palavras-chave: Vida e Evolução; Geometria; Produto Educacional; Jogo didático; Interdisciplinaridade.

Abstract: The objective of this study is to present a domino game using heredograms as an integrating theme between the area of Natural Sciences (NS) and the area of Mathematics (M). This is an educational product developed in the course "Teaching Science and Mathematics in Early Childhood" within a Professional Master's Degree from a university in southern Brazil. A domino game involving geometry and the heredogram symbols was built to simplify the understanding of NS and M concepts from an interdisciplinary perspective. The game was applied to a group of students and had its findings validated at a university event. Therefore, after the application and validation of the "Heredogram Domino" game, which explored geometric shapes transposed into heredogram symbols, it was found that this game had contributed positively to the student teaching and learning process. As a result, it may be replicated and recontextualized in other teaching situations and school stages.

Keywords: Life and Evolution; Geometry; Educational Product; Educational Game; Interdisciplinarity. 


\section{INTRODUÇÃO}

O currículo, nos anos iniciais do Ensino Fundamental (EF) vem sendo orientado pela Base Nacional Curricular Comum Curricular (BNCC) (BRASIL, 2017) para ser implementado de modo interdisciplinar. Paviani (2014) e Fazenda (2008) ao referiremse à interdisciplinaridade no ambiente escolar relatam que se trata de uma experiência didática que presume o diálogo entre as disciplinas em situação de interlocução dos conhecimentos afins. Ainda segundo os autores, o princípio da interdisciplinaridade não se trata de um fenômeno homogêneo, linear e uniforme.

Desta forma, os docentes pelas escolhas dos objetos de conhecimentos e temas de estudo podem potencializar a interlocução de saberes das áreas do conhecimento em diferentes níveis, formas e tipos (Ciências Humanas, Ciências da Natureza, Matemática e Linguagens). Assim, em se tratando da articulação entre áreas do saber como Ciências da Natureza (CN) e Matemática $(\mathrm{M})$, podem valerem-se de conteúdos e recursos didáticos capazes de mobilizar conhecimentos e processos interdisciplinares, os quais ancoram-se nos objetos de conhecimento passíveis de serem abordados por diferentes áreas.

O recurso didático heredograma ${ }^{1}$ é utilizado pela área da $\mathrm{CN}$ para representações do pedigree de uma família por meio de signos, porém seus símbolos expressam-se por meio de formas geométricas. Assim, analisando o tratamento particular dado a cada área $(\mathrm{CN}$ e $\mathrm{M})$ acrescenta-se que esse recurso didático muito embora empregado na genética tem potencial de alavancar os estudos tanto das $\mathrm{CN}$ quanto da $\mathrm{M}$, quer seja, explorando os elementos matemáticos envolvidos na construção dos heredogramas (formas geométricas), quer realizando representações de famílias observando sua ascendência e descendência, bem como analisando características hereditárias. Outrossim destaca-se que pode ser trabalhado em diferentes etapas escolares incluindo os anos iniciais (VESTENA, 2016).

Diante do exposto, o presente artigo objetiva apresentar um jogo de Dominó, utilizando os heredogramas como temática articuladora entre a área das CN e M. Esse recurso foi aplicado com estudantes da rede municipal do ensino fundamental e

\footnotetext{
${ }^{1}$ Segundo Vestena (2015) heredogramas representam a estruturas de famílias, por várias gerações, empregando símbolos padronizados internacionalmente. Os símbolos empregados são formas geométricas planas, tais como: círculo e circunferência, quadrado e região quadrada, dentre outras.
} 
validado em um evento universitário da região central do estado do Rio Grande do Sul, Brasil.

\section{CIÊNCIAS E MATEMÁTICA NUMA PERSPECTIVA INTERDISCIPLINAR}

Para BNCC (BRASIL, 2017), as instituições de ensino da educação básica necessitam fortalecer a competência pedagógica das equipes escolares para adotar estratégias mais dinâmicas, interativas e colaborativas em relação ao processo de ensino e aprendizagem dos estudantes. Precisam decidir sobre as formas de organizarem os componentes curriculares de modo interdisciplinar observando as competências gerais para a educação básica a fim de,

exercitar a curiosidade intelectual e recorrer à abordagem própria das ciências, incluindo a investigação, a reflexão, a análise crítica, a imaginação e a criatividade, para investigar causas, elaborar e testar hipóteses, formular e resolver problemas e criar soluções (inclusive tecnológicas) com base nos conhecimentos das diferentes áreas do saber (BRASIL, 2017, p.9).

A partir dessa compreensão pode-se buscar nas orientações da BNCC a respeito do currículo escolar (eixo temático, objeto de conhecimento e habilidades) temas e conhecimento que viabilizem a conexão, por exemplo, entre áreas do conhecimento como M e CN. Assim sendo, nas $\mathrm{CN}$ pode-se a partir das características dos seres vivos (reprodução sexuada e hereditariedade) buscar suporte nos conhecimentos tanto na Biologia quanto M para estudar, analisar e registrar dados empregando por meio de representações gráficas e estudar as formas geométricas envolvidas na representação gráfica (pedigree) dos indivíduos por meio de heredogramas. Segundo Marandino (2005) a abordagem de um conceito escolhido que, a priori parte de uma área do currículo escolar (saber ensinado) pode não se encontrar de forma pura no saber de referência (saber sábio), sendo assim um tema pode emergir de diferentes áreas de conhecimento.

Portanto, os objetos de conhecimentos (hereditariedade, heredogramas e formas geométricas) são passíveis de serem tratados no currículo escolar dentro de um percurso metodológico interdisciplinar.

O Quadro 1 expõe os objetos de conhecimentos pautados como possibilidades interdisciplinares entre as áreas das $\mathrm{CN}$ e $\mathrm{M}$, nos anos iniciais do EF, viabilizados pela proposta interdisciplinar que faz uso da representação gráfica de famílias por meio de heredogramas.

Quadro 1 - Áreas e objetos de conhecimentos (BRASIL, 2017) 


\begin{tabular}{|l|l|}
\hline Matemática & $\begin{array}{l}\text { Localização espacial; } \\
\text { Pontos de referência; } \\
\text { Figuras geométricas espaciais e planas. }\end{array}$ \\
\hline Ciências da & $\begin{array}{l}\text { Características dos seres vivos; } \\
\text { Reprodução sexuada; } \\
\text { Natureza }\end{array}$ \\
\hline
\end{tabular}

Assim, para expor como os conhecimentos das CN e M são tratados em cada área e podem ser relacionados entre si, o Quadro 2 traz em (A) para área das $\mathrm{CN}$, os símbolos e significados empregados em heredogramas, em (B) um exemplo de heredograma e em (C) a interpretação de um heredograma.

Quadro 2- símbolos, significados e interpretação de heredograma (VESTENA; LORETO, 2016)

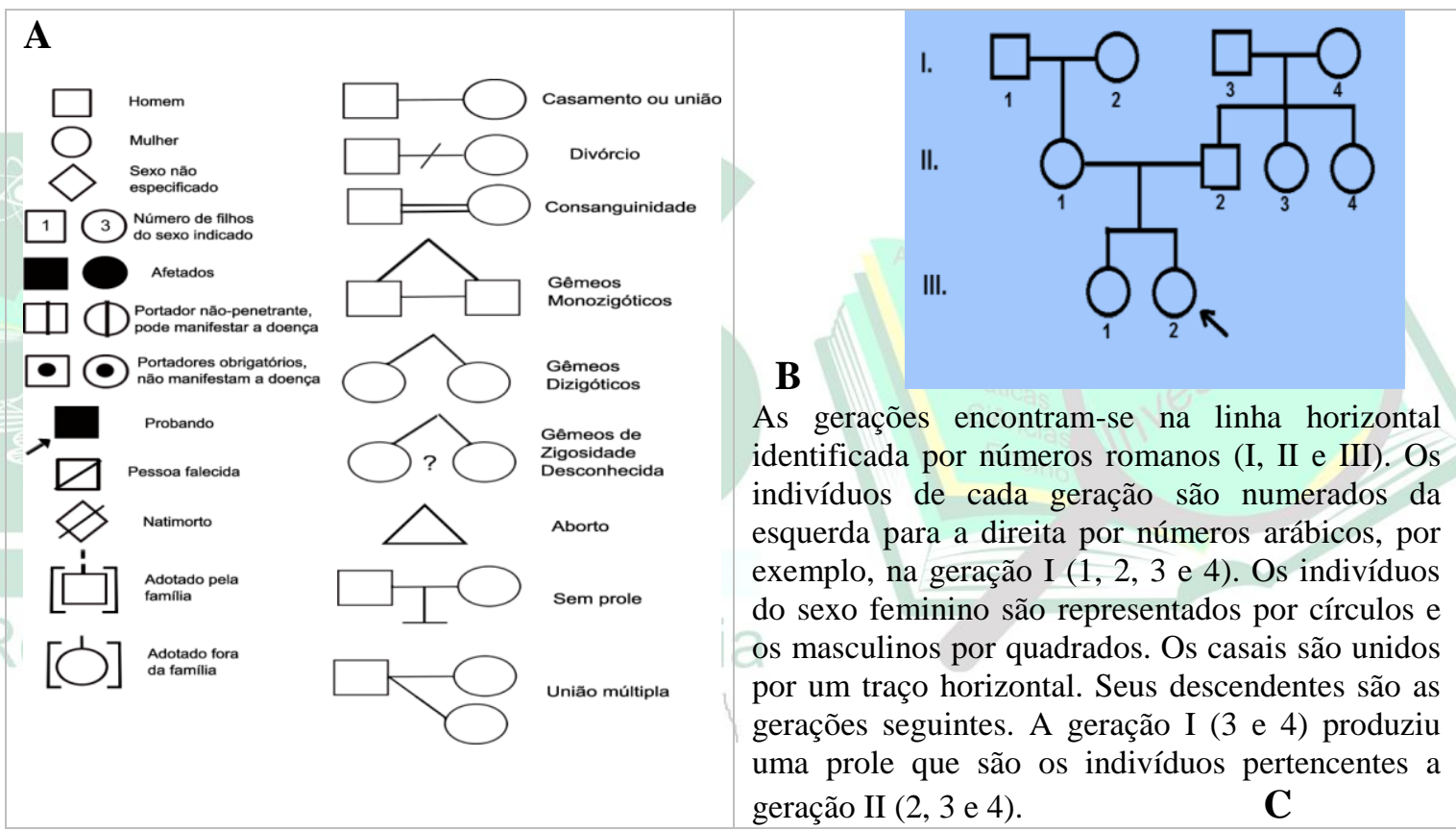

Sob a perspectiva da área da M, o Quadro 3 traz em (A) as formas geométricas que podem estar envolvidas nos heredogramas e, em (B) as definições das formas geométricas segundo Dolce e Pompeo (1993).

Quadro 3- formas geométricas e definições

\begin{tabular}{|l|l|}
\hline Q & $\begin{array}{l}\text { B Quadrado: é um quadrilátero plano convexo. Só é um quadrado se, } \\
\text { possuir os quatro ângulos congruentes e os quatro lados congruentes. } \\
\text { Círculo ou disco: é um conjunto dos pontos de um plano cuja distância } \\
\text { à um ponto dado desse plano é menor ou igual a uma distância (não } \\
\text { nula) dada. Triângulo: dados os três pontos A, B e C não colineares, à } \\
\text { reunião de segmentos AB, AC e BC chama-se triângulo ABC. Losango: } \\
\text { um quadrilátero plano convexo. É um losango se, e somente se, possuir } \\
\text { os quatro lados congruentes. }\end{array}$ \\
\hline
\end{tabular}




\title{
3. JOGOS COMO RECURSOS DIDÁTICOS
}

Os jogos põem em exercícios funções cognitivas e afetivas e, assim desenvolvem conteúdos sociais. Dentro do processo de construção e reconstrução do conhecimento, podem auxiliar o aluno a interagir, refletir, visualizar, rever suas teorias e concepções alternativas, desenvolvendo habilidades e buscando a autonomia na construção de conhecimentos (FELBER; KRAUSE; VENQUIARUTO, 2018).

Muitos jogos se mantêm praticamente inalterados desde sua criação até nossos dias (WEISS; WEISS, 2015). Assim, no passado e na contemporaneidade tem-se variados jogos que podem ser utilizados de forma individual ou coletiva (HUIZINGA, 2017). São jogos como xadrez, dominó, quebra-cabeças, tabuleiros com diferentes desafios, jogos que envolvem disputas corporais e os jogos digitais que podem ser usados em rede ou não. No entanto, apesar dos jogos estarem presentes na vida diferentes contextos da humanidade nem sempre foram pensados como recursos didáticos escolares (FORTUNA, 2019).

Em se tratando do jogo de dominó, segundo Kiya e Dionísio (2014) teve origem chinesa, tornou-se conhecido por volta de 1900 e a origem do nome "dominó" vem da expressão latina Domino gratias (graças a Deus). Assim sendo, o jogo de dominó pode ser adaptado como recurso escolar a fim de acionar conhecimentos transpondo o seu design e a dinâmica de como jogar para uma proposta didática e com potencial de articular conhecimentos e habilidades escolares.

\begin{abstract}
Essas estratégias encontram-se vinculadas ao uso de ferramentas e materiais que são os produtos educacionais. Portanto, por produtos educacionais entendem-se os materiais didáticos elaborados com o objetivo de mediar o processo de ensino e aprendizagem. Sua natureza é diversa, podendo ser jogos didáticos, protótipos e roteiros para atividades experimentais, mídias educacionais, propostas e sequências de ensino, livros paradidáticos, materiais interativos, aplicativos, entre outros (ROSA; LOCATLLI, 2018, p.27).
\end{abstract}

Neste viés, apresenta-se aqui um jogo de dominó que envolve saberes das $\mathrm{CN}$ e M. No âmbito das CN, aborda-se no jogo o estudo dos heredogramas, que envolve conceitos como reprodução sexuada, genética e hereditariedade. Já no âmbito da matemática, pode-se explorar os símbolos e formas geométricas presentes nos heredogramas, tais como: círculo e circunferência, quadrado e região quadrada, retângulo e região retangular, triângulo e região triangular. Pode-se, portanto, explorar saberes tanto das $\mathrm{CN}$ quanto da M na aplicação deste jogo. Assim, o jogo de dominó permite a experiência de identificação e memorização das formas geométricas/símbolos 
presentes ou não em heredogramas e, em uma próxima etapa, os docentes podem desafiar os estudantes construir seus próprios heredogramas familiares. Nessa oportunidade podem construir e empregar de modo correto as formas geométricas/símbolos dos heredogramas de forma concreta.

\section{PERCURSO METODOLÓGICO, PROCESSO E PRODUTO}

A disciplina CN e M para Infância do Mestrado Profissional do RS, Brasil, se destina à formação continuada de pedagogos e é exercida em situação de bidocência ou seja, professores da área da $\mathrm{M}$ e das $\mathrm{CN}$ atuando nas aulas conjuntamente. A disciplina prima pela interlocução de saberes das duas áreas em propostas interdisciplinares. Assim, foi escolhida a temática das representações familiares por heredogramas uma vez que ela pode aproximar as áreas de $\mathrm{M}$ e CN pela exploração de modo simultâneo das formas geométricos e dos signos para expressar os elos familiares em heredogramas. Dessa forma, foi possível construir um produto educacional no formato de um jogo de dominó. "No âmbito dos mestrados profissionais, os produtos educacionais igualmente se valem de perspectivas teóricas para sua fundamentação e buscam proporcionar uma maior aproximação entre os estudantes e os conteúdos escolares" (ROSA; LOCATLLI, 2018, p.33).

Nesse sentido o Quadro 4, sumariza os objetivos do jogo denominado "Dominó do Heredograma”, eixos temáticos envolvidos, público alvo, materiais empregados na sua confecção e modo de jogar.

Quadro 4- objetivos do jogo, eixos temáticos envolvidos, público alvo, materiais empregados na sua confecção e modo de jogar.

\begin{tabular}{|c|c|}
\hline Título & DOMINÓ DO HEREDOGRAMA \\
\hline $\begin{array}{l}\text { Objetivo } \\
\text { geral }\end{array}$ & $\begin{array}{l}\text { Estudar as formas geométricas e símbolos do heredograma para compreender os conceitos } \\
\text { matemáticos e científicos envolvidos em sua estrutura gráfica. }\end{array}$ \\
\hline $\begin{array}{l}\text { Objetivos } \\
\text { específicos }\end{array}$ & $\begin{array}{l}\text { Identificar a nomenclatura das figuras geométricas e os significados dos símbolos } \\
\text { constantes do jogo; } \\
\text { Correlacionar as formas geométricas aos símbolos na estrutura de um heredograma; } \\
\text { Caracterizar os seres vivos pela reprodução sexuada; Compreender a estrutura de uma } \\
\text { família pelos seus ascendentes, descendente e geração (pedigree) }\end{array}$ \\
\hline $\begin{array}{l}\text { Eixos } \\
\text { temáticos }\end{array}$ & $\begin{array}{l}\text { Geometria }(\mathrm{M}) \\
\text { Vida e Evolução }(\mathrm{CN})\end{array}$ \\
\hline $\begin{array}{l}\text { Público } \\
\text { alvo }\end{array}$ & Anos finais do ensino fundamental. \\
\hline Materiais & $\begin{array}{l}12 \text { placas em "MDF" medindo } 14 \times 6 \mathrm{~cm} \text {, papel adesivo, caneta, símbolos e significado do } \\
\text { heredograma, peças geométricas (quadrado, triângulo e losango }(5 \mathrm{~cm}) \text { e o círculo } \\
(2,5 \mathrm{~cm}) \text {, dois círculos pretos, um quadrado preto, um triângulo branco, seis quadrados } \\
\text { brancos, sete círculos. }\end{array}$ \\
\hline Modo & Dois participantes sendo que cada jogador recebe seis peças com formas geométricas e \\
\hline
\end{tabular}




\begin{tabular}{|l|l|}
\hline Jogar & $\begin{array}{l}\text { ícones utilizados em heredogramas. O primeiro a jogar é aquele que recebeu a peça com a } \\
\text { palavra 'início'. O objetivo é baixar todas as peças. Cada participante completa sua jogada } \\
\text { através da coincidência da forma geométrica de duas peças ou de indivíduos, arranjos } \\
\text { conjugais de uma família pelos ícones (simbologias) de heredogramas. Após a montagem } \\
\text { do dominó, ganhará o jogo quem sobrepor as peças geométricas espaciais em cima das } \\
\text { que estão representadas no dominó. }\end{array}$ \\
\hline
\end{tabular}

O Jogo "Dominó do heredograma" é composto de 12 peças com informações (significados biológicos) e de 16 formas geométricas avulsas (quadrados, círculos, losango e triângulos) para serem sobrepostos às peças do dominó quando aparecem no jogo. A Figura 1 apresenta o jogo e as peças avulsas.

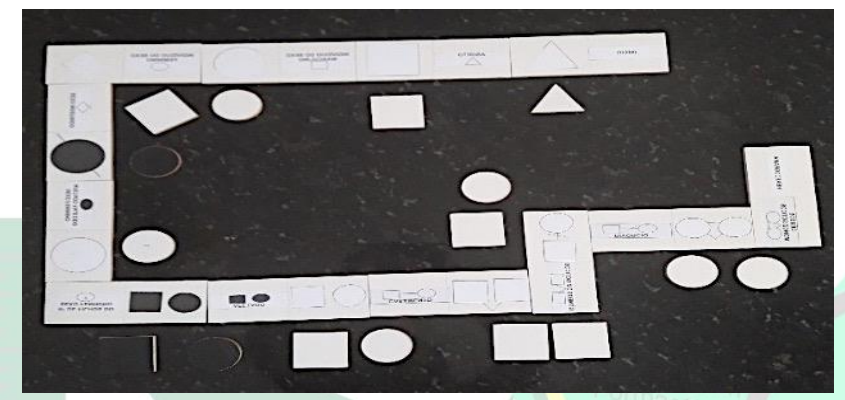

Figura 1- jogo "Dominó do heredograma” e formas geométricas empregadas em heredogramas.

O Quadro 5 apresenta as 12 peças do jogo de dominó sendo que nas duas extremidades Esquerda (E) e Direita (D) encontram-se informações que exploram as formas geométricas com suas denominações e também os símbolos e os significados encontrados na representação de heredogramas.

Quadro 5- descrição e imagens das peças do jogo "Dominó do heredograma" com os signos para a área da Matemática (M) formas geométricas e das Ciências da Natureza $(\mathrm{CN})$ em heredogramas.

1': Esquerda (E) início do jogo. Direita (D) o triângulo.

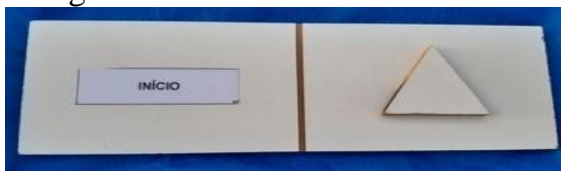

$\mathbf{2}^{\mathbf{a}}: \mathbf{E}$ aborto e triângulo (símbolo). D forma geométrica (quadrado).

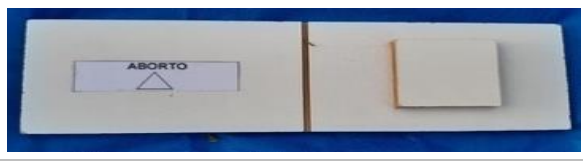

$7^{\mathrm{a}}$ : $\mathbf{E}$ número de filhos do sexo feminino (círculo com o $\mathrm{n}^{\circ} 2$ ). D círculo e um quadrado pretos (afetados).

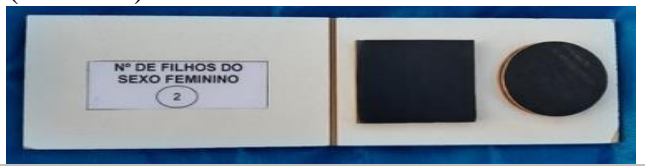

$\mathbf{8}^{\mathbf{a}}$ : $\mathbf{E}$ círculo e quadrado pretos (afetados).D quadrado e círculo brancos unidos por linha horizontal (casamento).

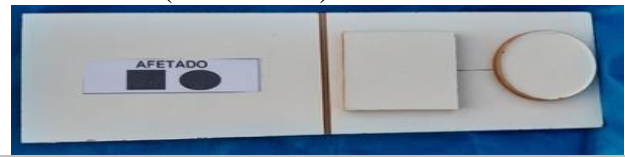




\section{RIS}

$\mathbf{3}^{\mathbf{a}}$ : E quadrado (sexo masculino). D círculo.

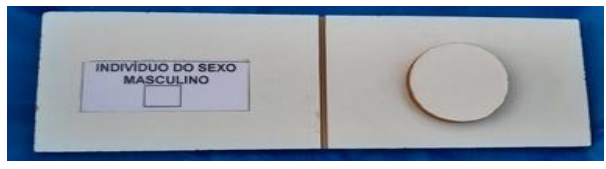

$4^{\text {a }}$ : E círculo (sexo feminino). D forma geométrica losango.

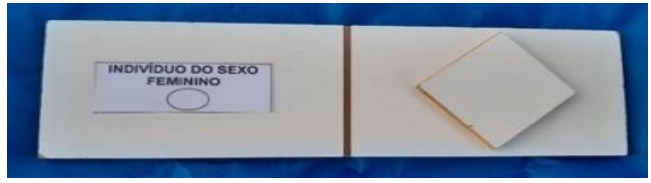

$5^{\text {a }}$ : E losango (sexo indefinido). D o círculo preto (indivíduo afetado) cruzado por linha diagonal (falecido).

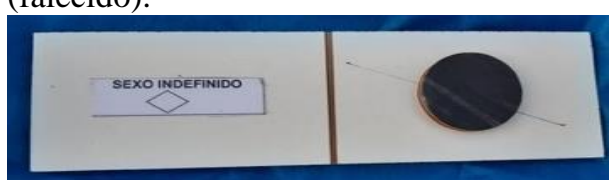

$\mathbf{6}^{\mathbf{a}}: \mathbf{E}$ círculo preto cortado por linha diagonal (sexo feminino afetado e falecido). D o círculo branco com $\mathrm{n}^{\circ} 2$ (dois indivíduos do sexo feminino).

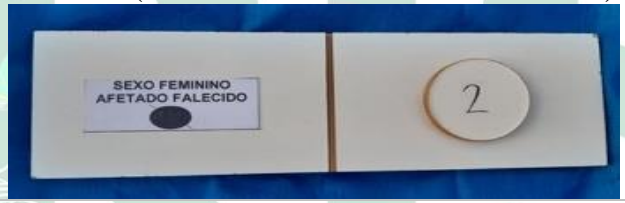

9ª $^{\mathbf{a}} \mathbf{E}$ círculo e quadrado brancos ligados (casamento). D quadrados brancos com ligação em vértice (gêmeos dizigóticos).

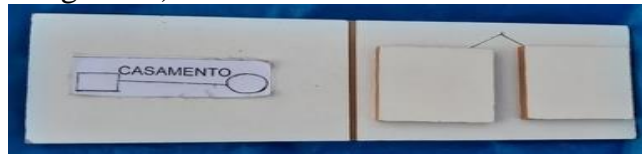

$\mathbf{1 0}^{\mathbf{a}}$ : $\mathbf{E}$ quadrados brancos unidos em vértice (gêmeos dizigóticos). D quadrado e círculo brancos unidos por uma linha horizontal cruzada por uma linha diagonal (casal separado).

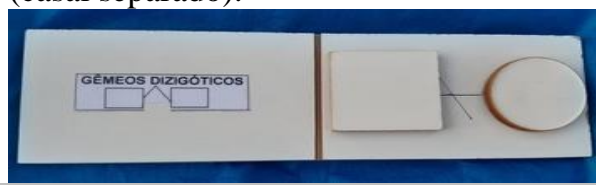

11 ${ }^{\mathbf{a}}$ : E quadrado e um círculo ligados e cortados com linha diagonal (separação). D dois círculos brancos unidos entre si e em vértice (gêmeos monozigóticos)

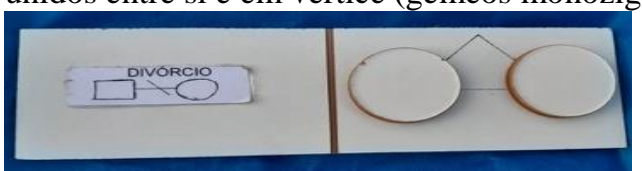

12 $\mathbf{a}$ : $\mathbf{E}$ dois círculos brancos unidos entre si e em vértice (gêmeos monozigóticos). D a palavra heredograma.

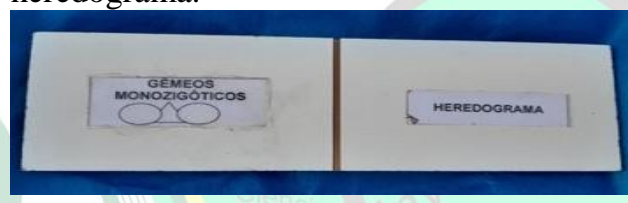

O jogo de dominó foi testado junto a estudantes dos anos iniciais do EF da classe especial e, desse modo, pode ser avaliado de maneira qualitativa, em função de se considerar os conhecimentos construídos durante as aulas que foram acionados mediante a aplicação do recurso didático "Dominó do heredograma".

A sequência de atividades que incluiu o jogo de "Dominó do heredograma" foi aplicada em um turno uma classe de alunos especiais de um município do RS, Brasil e mediadas pela professora regente que também é uma das autoras deste estudo. A Figura 2 representa a aplicação referido jogo junto aos estudantes.

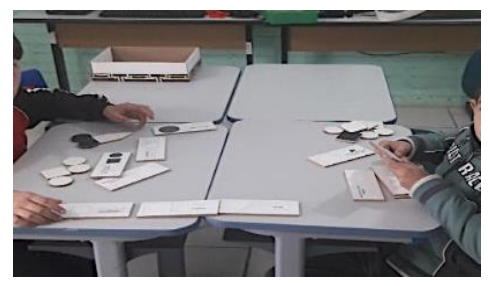

Figura 2- Aplicação do jogo

As atividades que envolveram o jogo foram propostas em quatro momentos pela professora aos estudantes. Em um primeiro momento os alunos foram sensibilizados 
(apresentação do jogo, suas as características e seus objetivos) e, após foram desafiados a interagirem jogando com o "Dominó do heredograma". Em um segundo momento houve o aprofundamento dos estudos acionados pelo jogo. Desse modo, foi distribuído textos e livros didáticos para trabalhar os conceitos envolvidos como nas $\mathrm{CN}$ características dos seres vivos (reprodução e hereditariedade) e na M (formas geométricas). No terceiro momento, para sistematização dos conhecimentos foi disponibilizado materiais como lápis e cartolinas para o registro em painéis das formas geométricas/simbologias dos heredogramas e do heredograma do núcleo familiar que convivem. Em um quarto momento como culminância houve a socialização dos registros com os colegas.

O presente estudo é de abordagem qualitativa e documental. Segundo BOGDAN e BIKLEN (1994) a perspectiva qualitativa trabalha com o universo dos significados, considerando as crenças, as motivações, as aspirações, os valores, as atitudes e, portanto, analisa a profundidade das relações pessoais e destas com os objetos.

Os dados analisados foram os registros gráficos (painéis, desenhos, anotações) produzidos pelos estudantes durante as atividades que envolveram a aplicação do jogo. Essas informações foram fotografadas por uma das pesquisadoras com o intuito de analisar em primeira mão as informações nelas contidas, visto que não receberam, qualquer tratamento analítico. Os documentos analisados foram: documentos oficiais e apontamentos nos cadernos didáticos dos estudantes registrados pelos docentes como imagens fotográficas (BOGDAN; BIKLEN,1994).

\section{ANÁLISE DOS DADOS}

Os materiais analisados referem-se ao terceiro momento da sequência (sistematização) produzidos pelos alunos que participaram das atividades que incluíram o jogo "Dominó do heredograma". Desse modo, pode-se perceber as potencialidades do jogo para promover a interlocução de saberes das áreas da $\mathrm{M}$ e $\mathrm{CN}$ numa perspectiva interdisciplinar. Foram analisados os dados de quatro estudantes e, somente o material produzido em sala de aula. O Quadro 6 compila os registros dos estudantes em painéis dos seus estudos.

Quadro 6- Registros dos estudantes da etapa de sistematização em painéis.

\begin{tabular}{|l|l|l|}
\hline $\mathbf{A}$ & $\mathbf{A}$ & $\mathbf{2}^{\mathbf{a}}$ \\
\hline
\end{tabular}



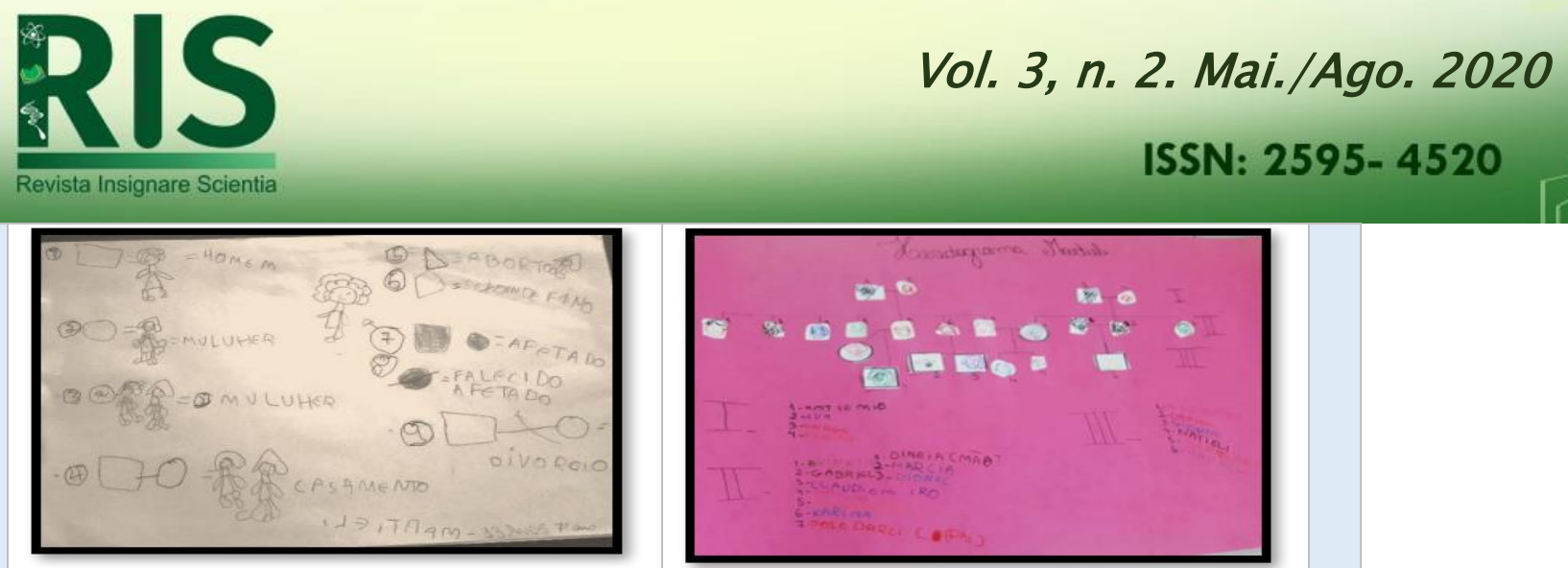

B $1 \mathrm{~B}$

2B
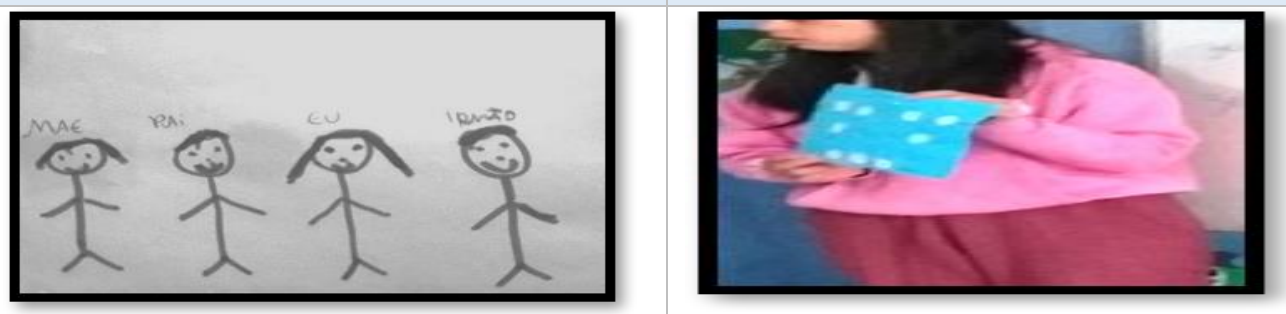

C $\quad 1 \mathrm{C}$

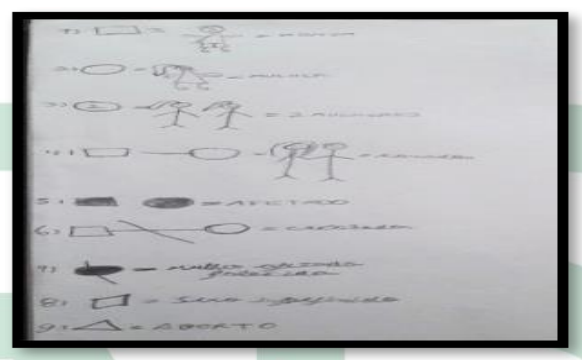

2C

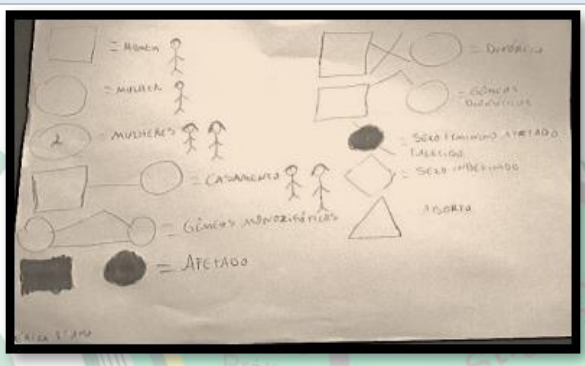

Em A, observa-se os registros de um estudante em sequência. Primeiro em 1A houve a expressão das formas geométricas e dos principais símbolos empregados em heredogramas, porém com dificuldades no traço o que pode estar relacionado às dificuldades de ordem psicomotoras. Quanto aos desenhos, o estudante, procurou detalhar algumas diferenças físicas, especialmente entre os sexos feminino e masculino. $\mathrm{Na}$ sequência em $2 \mathrm{~A}$, na representação o heredograma, o estudante representou os indivíduos, sexos, casamentos, falecimentos, descendências e gerações, além de apresentar três gerações e procurar identificar com os nomes os integrantes do pedigree familiar.

O estudante $\mathrm{B}$ desenhou em 1B as pessoas que moram em seu núcleo familiar, sendo que o esquema corporal se apresenta na forma estereotipada 'palito' e em 2B construiu o heredograma da sua família com três gerações expressando a representação dos sexos, casamentos, descendentes (prole), porém, comparando com o desenho 1B com os registros em $2 \mathrm{~B}$, no primeiro constam dois irmãos, no heredograma (2B) são três. Segundo a docente o terceiro indivíduo, trata-se da irmã recém-nascida que não foi registrada no desenho. 
Os registros expressos em C são de dois estudantes $\mathrm{C} 1$ e C2, observa-se que representaram algumas formas geométricas e os símbolos empregados em heredogramas (sexos, casamento, separações conjugais, falecimento, indivíduos afetados, aborto, gêmeos e sexo indefinido). Quanto aos desenhos apresentam poucas diferenças físicas, pois predominou o formato estereotipado 'palito`. Em relação aos heredogramas esses não foram analisados, pois não foram construídos em sala de aula. Os alunos ocuparam o tempo disponível para expressar, formas geométricas, símbolos e nomenclaturas.

Pelos registros obtidos e analisados constatou-se que a proposta didática que incluiu o jogo do "Dominó do heredograma" auxiliou instigando os estudantes na compressão dos conceitos que estavam sendo mediados pela docente. Evidenciou-se que os mesmos estruturaram painéis registrando seus estudos no que diz respeito às formas geométricas e aos símbolos do heredograma, de forma a atingirem os propósitos curriculares estipulados para os anos iniciais. No entanto, assume-se que algumas atividades precisam ser retomadas e aprofundadas. Segundo a BNCC, nos anos iniciais, os conhecimentos precisam ser apresentados e/ou aprofundados e/ou consolidados conforme sua complexidade. Assim, tanto os conceitos inerentes a geometria quanto aos voltados à reprodução sexuada e hereditariedade precisam ser abordados nos anos finais do EF e no ensino médio.

Então, nos anos iniciais, a atividade cumpriu o papel de sensibilizar os estudantes para abordar em sala de aula habilidades da área da M, tais como: identificar, nomear figuras planas (círculos, quadrado, retângulo, triângulo) em desenhos apresentados em diferentes disposições ou em contornos de faces sólidos geométricos; reconhecer, comparar e nomear figuras planas (círculo, quadrado, retângulo e triângulo) por meio de características comuns em desenhos apresentados em diferentes disposições ou em sólidos geométricos e classificar e comparar figuras planas (triângulo, quadrado, retângulo, trapézio, paralelogramo) em relação a seus lados (quantidade, posições relativas e comprimento) e vértice (BRASIL, 2017).

Segundo Oliveira e Leivas (2016), com a Geometria, pode-se acionar, nos anos iniciais, habilidades e competências relacionadas ao pensamento geométrico, como espaço e forma.

Desse modo, é pertinente trabalhar com situações de aprendizagem que levem o aluno a estabelecer relações entre figuras espaciais e suas representações planas, envolvendo sua observação sob diferentes pontos de vista, construindo e interpretando suas representações (OLIVEIRA; LEIVAS, 2016, p.109). 
Com relação a área das $\mathrm{CN}$, tomando como referência a $\mathrm{BNCC}$, pode-se contemplar por meio do presente produto habilidades como: identificar características sobre o modo de vida (o que comem, como se reproduzem, como se deslocam etc.) dos animais mais comuns no ambiente próximo. Para essa habilidade, o foco estaria na reprodução sexuada e sua finalidade como ciclo vital, hereditariedade e perpetuação da espécie. Comparar características físicas entre os colegas, reconhecendo a diversidade e a importância da valorização, do acolhimento e do respeito às diferenças e localizar, nomear e representar graficamente (por meio de desenhos) partes do corpo humano e explicar suas funções (BRASIL, 2017). Assim, dentre as atividades propostas aos estudantes destaca-se que a última habilidade foi trabalhada por meio da representação gráfica (desenhos e painéis) da família do estudante e da socialização entre os colegas. Segundo Ainsworth; Prain; Tytler (2011) as representações visuais como desenhos, diagramas e gráficos criam novas relações entre os fatos e as ideias, testam e elaboram conhecimentos, como também, oportunizam a livre expressão.

Nesse contexto, entende-se que o jogo de dominó como recurso didático proporcionou de forma concreta, lúdica e criativa, a interlocução entre a área das $\mathrm{CN}$ e $\mathrm{M}$, envolvendo os símbolos usados na construção do heredograma, ou seja, explorando conceitos, identificação e nomenclatura das peças em formas geométricas (círculo e circunferência, quadrado e região quadrada, retângulo e região retangular, triângulo e região triangular), bem como, manuseando e explorando a criatividade, a memória, o raciocínio lógico, a capacidade de observação, atenção e concentração; promover a oralidade e a socialização (BRASIL, 2017).

\footnotetext{
A interdisciplinaridade é uma categoria de ação. Não significa a integração entre os conteúdos de diferentes disciplinas, antes de tudo, constitui-se em um diálogo entre os indivíduos para, só depois, concretizar-se na interrelação entre as disciplinas do currículo escolar visando um processo interno de conhecimento (FAZENDA, 2008).
}

Portanto, o recurso didático "Dominó do heredograma" utilizado pelos alunos com necessidades especiais oportunizou concretamente a exploração do material, incitou a memória, a identificação e nomenclatura das formas geométricas e símbolos utilizados em heredogramas para que, em uma etapa posterior subsidiar a aquisição de novos conhecimentos acerca das áreas das $\mathrm{CN}$ e $\mathrm{M}$.

O jogo de dominó foi apresentado pela professora regente acompanhada pelos seus alunos da classe especial na III Mostra de Ciências e Matemática realizada em uma 
Universidade da região. Esse foi avaliado por uma banca técnica e, assim obteve sua validação. O grupo, na ocasião, foi agraciado com o $1^{\circ}$ lugar na categoria na qual se habilitaram.

\section{CONSIDERAÇÕES FINAIS}

O trabalho apresenta o jogo "Dominó do Heredograma e sintetiza os resultados de sua aplicação junto aos estudantes do EF com o intuito sensibilizá-los ao estudo de conceitos inerentes à área da M e CN explorando formas geométricas transpostas em símbolos empregado em heredograma. Deste modo constatou-se que o jogo tem potencial de acionar e aprofundar conhecimentos acerca de das formas geométricas espaciais e planas e, também dos símbolos empregados em heredogramas, bem como, dos elos genéticos de uma família.

Portanto, o jogo de dominó oportunizou aos estudantes que os conceitos das $\mathrm{CN}$ e $\mathrm{M}$ fossem abordados de modo interdisciplinar. Assim sendo, após a aplicação e validação do jogo de "Dominó do heredograma" constatou-se que esse contribuiu positivamente no processo de ensino e aprendizagem dos estudantes e, dessa forma tem potencial de ser replicado e recontextualizado em outras situações de ensino e etapas escolares.

\section{REFERÊNCIAS}

AINSWORTH, S.; PRAIN, V.; TYTLER, R. Drawing to Learn in: Science Education, v.333, n.26, p.1096-1097, ago. 2011. Disponível em: http://product.design.umn. Acesso em: 28 fev. 2020.

BRASIL. Ministério da Educação. Base Nacional Comum Curricular. BNCC, de 14 de dezembro de 2017. Disponível em: http://basenacionalcomum.mec.gov.br/ Acesso em 2 de fev. 2020.

BOGDAN, R. C.; BIKLEN, S. K. A investigação qualitativa em educação: uma introdução à teoria e aos métodos. Portugal: Porto Editora, 1994.

COSTA, M, T, A. Metodologia do ensino da educação especial. 1.ed. Curitiba: IESDE Brasil, 2017.

DOLCE, O.; POMPEU, J. N. Fundamentos de matemática elementar: geometria plana. 7.ed. São Paulo: Atual, 1993.

FAZENDA, I. (Org.). O que é interdisciplinaridade? São Paulo: Cortez, 2008. 
FELBER, D.; KRAUSE, J.; VENQUIARUTO, L. O uso de jogos digitais como ferramenta de auxílio para o ensino de Física. Revista Insignare Scientia, v. 1, n. 2, 2018. Disponível em: https://periodicos.uffs.edu.br/index.php/RIS/article/view/8152/5645 Acesso em: 30 Maio de 2020.

FORTUNA, T. R. Em busca da pedagogia lúdica: como brincam os professores que brincam em suas práticas pedagógicas? Revista Eletrônica Ludus Scientiae. Foz do Iguaçu. v. 03, n. 01, p. 01-19, 2019. Disponível em: https://revistas.unila.edu.br/relus/article/view/1880/1735. Acesso em 22 de Fev. 2020. HUIZINGA, J. Homo ludens: o jogo como elemento da cultura. 8. ed. São Paulo, SP: Perspectiva, 2017.

KIYA, M. C. S.; DIONÍZIO, F. o uso de jogos e de atividades lúdicas como recurso pedagógico facilitador da aprendizagem. Caderno pedagógico. Programa de Desenvolvimento Educacional, da Secretaria de Estado da Educação do Paraná, 2014. MARANDINO, M.A pesquisa educacional e a produção de saberes nos museus de ciências. Anais... IV congresso mundial de museus e centro de ciências. História, ciência, saúde, Manguinhos, Museus de Ciências. Fundação Oswaldo Cruz, casa de Oswaldo Cruz, 2005, Rio de Janeiro, v.12, p. 161-171.

OLIVEIRA, M, T. LEIVAS, J, C, P. Visualização e representação geométrica com suporte na Teoria de Van Hiele. Ciência e Natura, Santa Maria v.39 n.1, 2017, p.108117. Disponível em: https://periodicos.ufsm.br/cienciaenatura/article/viewFile/23170/pdf Acesso em: $30 \mathrm{de}$ abr.2020.

PAVIANI, J. Interdisciplinaridade: conceitos e distinções. 2. ed. Caixas do Sul: Educs, 2014.

ROSA, C.T.W; LCATELLI, A. Produtos educacionais: diálogo entre universidade e escola. Ensino de Ciências e Tecnologia em Revista, v. 8, n. 2, 2018. Disponível em: http://srvapp2s.urisan.tche.br/seer/index.php/encitec/article/view/2716/pdf-rosa Acesso em: 1 Jun. 2020.

VESTENA, R.F. Heredogramas familiares na educação básica: ensino e aprendizagem pela interdiscipliariedade e contextualização do conhecimento. Tese (Doutorado Educação em Ciências Química da Vida e Saúde). Santa Maria, RS, Brasil, 2015.

VESTENA, R. F.; LORETO, E.L.S. Representações familiares nos anos iniciais do 
ensino fundamental: desenhos, genealogias e heredogramas. Revista brasileira de ensino de ciências e tecnologia, 2016, v.9 n.3, p.1-18. Disponível em: https://periodicos.utfpr.edu.br/rbect. Acesso em: 20 de maio 2020.

WEISS, M.L. L.; WEISS, A. A intervenção psicopedagógica nas dificuldades de aprendizagem. Wak editora: Rio de Janeiro, 2015.

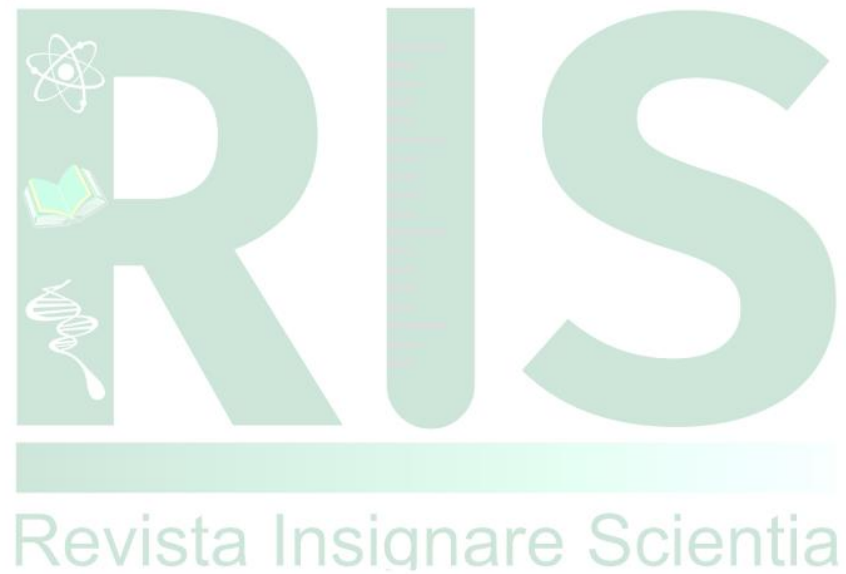

